\title{
Revisitando o triunvirato lógica/dialética/retórica ${ }^{\mathrm{i}}$
}

\section{Ralph H. Johnson}

Professor Emérito da Universidade de Windsor, Canadá

johnsoa@uwindsor.ca

Resumo: Muitos teóricos da argumentação adotaram a visão de que a argumentação pode ser abordada sob três perspectivas diferentes: a lógica, a dialética e a retórica, às quais denomino Triunvirato. Segundo Wenzel (1990), a base conceitual para esse triunvirato é a distinção entre argumentação como produto, como processo e como procedimento (a Distinção Tripartite). Neste artigo, quero levantar questões sobre a Visão do Triunvirato e a Distinção Tripartite na qual ela se baseia.

Palavras-chave: Teoria da Argumentação. Processo retórico. Procedimento dialético. Produto lógico.

Abstract: Many argumentation theorists have adopted the view that argumentation may be approached from three different perspectives: the logical, the dialectical and the rhetorical, which I refer to as the Triumvirate. According to Wenzel (1990), the conceptual foundation for this Triumvirate is the distinction between argumentation as product, as process and as procedure (the Tripartite Distinction). In this paper, I want to raise questions about the Triumvirate View and the Tripartite Distinction on which it is based.

Keywords: Argumentation theory. Rhetorical process. Dialectical procedure. Logical product.

\footnotetext{
' A Revista EID\&A agradece vivamente a Ralph Johnson pela autorização desta tradução do original "Revisiting the Logical/Dialectical/Rhetorical Triumvirate" publicado em Argument Cultures: Proceedings of OSSA, 09, 2009.
} 


\section{Introdução}

Muitos teóricos da argumentação (WENZEL, 1990; TINDALE, 1999; BLAIR, 2003; entre outros) citaram ou adotaram a visão de que a argumentação pode ser abordada sob três perspectivas diferentes: a lógica, a dialética e a retórica. Por razões reveladas mais adiante, denominei essas três perspectivas como "O Triunvirato". Tomo o artigo de Wenzel (1990) como o locus classicus para essa visão. Wenzel estabelece nesse texto uma base conceitual para tal triunvirato - a distinção entre argumentação como produto, como processo e como procedimento (a Distinção Tripartite) - e expõe a visão que ele chama de Perspectivismo. Esse artigo causou uma boa impressão, tendo sido citado por 22 pesquisadores, conforme mostra 0 Google Scholar, em março de 2009.

Apoio o espírito do pluralismo que marca a posição de Wenzel. No entanto, existem aspectos que me fazem pensar; por isso, quero levantar algumas preocupações sobre a Visão do Triunvirato e a Distinção Tripartite. Neste artigo, começo esboçando a história da Visão do Triunvirato. Em seguida, recapitulo a Visão do Triunvirato e a Distinção tripartite. Na seção posterior, assinalo minhas preocupações. E, para concluir, sugiro uma possível alternativa à concepção de Wenzel sobre tais questões.

\section{Um esboço da história da Visão do Triunvirato}

Nesta seção, esboço apenas um pouco da história da visão que estou considerando. Como todas as estradas sempre parecem voltar a Aristóteles, começamos por aí.

\section{Aristóteles}

As sementes da distinção podem ser encontradas em Aristóteles, pelo menos se seguirmos a leitura de Perelman em The Realm of Rhetoric (1982) [O império retórico]. Aristóteles desenvolveu a primeira lógica (seus Analíticos Anteriores e Analíticos Posteriores), apesar de o termo "lógica" só aparecer posteriormente ${ }^{1}$. Além disso, Aristóteles lida com o raciocínio dialético nos

\footnotetext{
${ }^{1}$ Pensa-se que Alexandre de Afrodisias tenha sido o propositor do termo (grato a John Woods pela referência).
} 
Tópicos e escreveu extensivamente sobre a Retórica como uma área de investigação. Note-se, no entanto, que, para Aristóteles, a retórica é um desenvolvimento a partir da dialética:

Aristóteles diz que a retórica, isto é, o estudo do discurso persuasivo, é uma "contraparte" (antístrofos) da dialética e que a arte retórica é um tipo de "consequência" (paraphues ti) da dialética e o estudo dos tipos de caráter. A correspondência com o método dialético é evidente: os discursos retóricos, assim como os argumentos dialéticos, procuram persuadir outros a aceitar certas conclusões com base em premissas que eles já aceitam. Portanto, as mesmas medidas úteis em contextos dialéticos serão, mutatis mutandis, úteis aqui: saber em quais premissas um dado tipo de auditório tende a acreditar e saber como encontrar premissas a partir das quais se chega à conclusão desejada (SMITH, 2017).

Com Aristóteles, então, encontramos o início de uma tradição na qual retórica, lógica e dialética são concebidas como campos com contribuições para o estudo da argumentação. Mas há tensão entre, por exemplo, retórica e filosofia (lógica), e a relação entre retórica e dialética é problemática. Durante grande parte desse período, a lógica é tratada como mais ou menos igual ao dialético ou à dialética (LEFF, 2002). No entanto, devemos lembrar que a lógica, como a pensamos hoje, só passou pelo seu maior desenvolvimento no final do século XIX e no início do século XX.

\section{Perelman}

Um dos proponentes mais vigorosos da perspectiva retórica é Perelman. Em O império retórico, Perelman discute lógica, dialética e retórica no processo de apresentar suas próprias visões sobre argumentação. Sua maneira de entender essas abordagens teve um papel formativo no desenvolvimento do que ele denomina A Nova Retórica, particularmente sua visão da lógica:

Certamente, é sabido que, na lógica moderna, [...] os lógicos matemáticos [...] identificam a lógica não com a dialética, mas com a lógica formal, com o raciocínio analítico de Aristóteles [ele quer dizer aqui os Analíticos Anteriores e Posteriores] e negligenciam completamente o raciocínio dialético como algo alheio à lógica (PERELMAN, 1982, p. 4).

$\mathrm{Na}$ visão de Perelman, há uma área de investigação denominada de “dialética”. Ela estuda o raciocínio dialético e "começa com teses aceitas de 
modo geral com o objetivo de obter aceitação de outras teses que podem ser ou são controversas" (PERELMAN, 1982, p. 2). Segundo Perelman, instâncias do raciocínio dialético não são compostas de uma série de inferências válidas e irrefutáveis (que seriam o assunto da lógica). O raciocínio dialético desenvolve argumentos mais ou menos fortes.

Estamos bem cientes de que tradicionalmente houve tensão entre lógica e retórica. Perelman parece resolver essa tensão abandonando mais ou menos a perspectiva lógica e introduzindo a dialética para lidar com certos aspectos da argumentação.

\section{Wenzel}

A partir dos anos 1970, Wenzel escreveu uma série de artigos sobre várias "perspectivas" sobre o estudo da argumentação (1990, p. 11-12). Neste artigo, concentro-me na versão de 1990, visto ser a mais madura. Segundo Wenzel, a argumentação consiste em um conjunto de atividades complexas nas quais as pessoas se envolvem para tomar decisões, resolver problemas e gerenciar desacordos em geral. Podemos tirar sua tese deste excerto:

A moral final deste ensaio deve agora estar clara: o julgamento humano depende da argumentação, e a argumentação depende igualmente dos recursos da retórica, da dialética e da lógica (WENZEL, 1990, p. 25-26).

Essa visão - que ele denomina Perspectivismo ${ }^{2}$ - distingue e relaciona três perspectivas ${ }^{3}$ sobre argumentação: a retórica, a dialética e a lógica. Essa visão surgiu de um animado debate sobre como estudar a argumentação e reconhece "a legitimidade de múltiplas abordagens" (WENZEL, 1990, p. 11). Cada uma dessas perspectivas, diz Wenzel (1990, p. 11), "está fundamentada na tradição do humanismo ocidental. Cada uma delas [...] assume algumas dessas atividades em seu escopo e as focaliza de maneiras distintas". Até os anos 1970, ao que parece, predominavam duas perspectivas: a lógica e a retórica. Todavia, Habermas, Zarefsky e Brockriede trouxeram a perspectiva

\footnotetext{
${ }^{2}$ Wenzel (1990, p. 11) toma esse termo de Brockriede.

3 Às vezes, "abordagens" e "pontos de vista". Numa discussão, Hansen perguntou: O que é uma perspectiva? O termo "perspectiva" não é definido aqui, nem "abordagem". Inicialmente, esse ponto não parecia importante, mas cheguei à conclusão de que a pergunta de Hansen levanta várias questões relevantes de que, no entanto, não posso tratar neste artigo.
} 
dialética de volta à equação ${ }^{4}$. "Para a concepção de argumentação como um processo retórico e um produto lógico, Brockriede acrescentou a noção de argumentação como método dialético" (WENZEL, 1990, p. 11).

É nesse excerto que encontramos, então, a origem do que estou chamando de Visão do Triunvirato. Cito Wenzel:

O Perspectivismo tem muito a recomendar. Primeiro, reconhece a legitimidade das múltiplas abordagens sobre a argumentação. Segundo, quando começamos a ver como diferentes tradições de pesquisa se baseiam em perspectivas distintas, podemos apreciar como cada tipo de pesquisa produz resultados únicos, como difere de outras abordagens, mas também como as perspectivas se relacionam umas com as outras [...] (WENZEL, 1990, p.11).

No restante de seu artigo de 1990, Wenzel detalha essas três perspectivas usando várias categorias diferentes: propósitos, escopo, foco, situação, recursos, critérios e papéis. Não posso, neste espaço, dedicar-me aos profícuos pormenores dessa discussão, mas recomendo a leitura.

$O$ que eu quero fazer agora, tendo finalizado este breve percurso histórico, é entender melhor a Distinção Tripartite e depois avançar para aprofundar nossa compreensão sobre as três perspectivas que, juntas, constituem o que eu chamo de Triunvirato.

\section{A Distinção Tripartite}

Wenzel escreve que:

[...] trabalhando de forma independente, mas quase ao mesmo tempo, [ele] construiu uma análise detalhada das três perspectivas, usando termos-chave semelhantes: processo retórico, procedimento dialético e produto lógico (WENZEL, 1990, p. 11).

Wenzel sugere que as noções de processo, procedimento e produto serão úteis para depurar as diferenças entre as perspectivas. Eu não sou tão otimista. Deixe-nos ver.

\footnotetext{
${ }^{4}$ No entanto, sabemos de discussões anteriores que a abordagem de Perelman reconhece a perspectiva dialética. Mesmo assim, parece que o dialético desapareceu em algum momento. Ela posteriormente reaparece com grande vigor com o surgimento da perspectiva dialética. Leff (2002, p. 53) diz: "Elas (dialética e retórica) não são entidades fixas, mas disciplinas em evolução".
} 
A distinção entre processo e produto me parece bastante sólida. Ela tem uma história de longa data aqui e em outras disciplinas. Em lógica, por exemplo, o termo "inferência” é entendido de forma ambígua, uma vez que pode se referir ao processo de gerar uma inferência e à inferência que resulta desse processo. É correto que, na maior parte das vezes, a lógica focaliza o produto. Contudo, dois comentários precisam ser feitos. Primeiro, a lógica dedutiva formal é, na minha avaliação, mais uma teoria da dedução do que uma teoria da argumentação. Em outros termos, a lógica formal estuda as normas que se aplicam a formas do tipo: Se P, então Q; P; portanto, Q. É inegável que, às vezes, argumentos assumem essa forma. Todavia, é altamente controverso que a lógica formal possa estabelecer as normas, os procedimentos, etc. necessários e suficientes para estudar toda a argumentação. Segundo, deve-se notar que existem abordagens lógicas focadas no processo, como a lógica do diálogo (cf. JOHNSON 2000, p. 290ss). Portanto, a perspectiva lógica não pode ser caracterizada com sucesso apenas em termos de foco no produto.

A distinção que Wenzel faz entre processo e procedimento me parece muito menos segura. Em nenhum lugar ele indica como diferenciaria esses dois termos cujos significados seriam normalmente considerados como muito próximos. Wenzel escreve:

De todos os significados do termo "dialética", o que emprego aqui considera a dialética como um método, um sistema ou um procedimento para regular as discussões entre as pessoas (WENZEL, 1990, p. 14).

Essa passagem sugere que Wenzel não está casado com a ideia de procedimento quando se trata de esmiuçar o termo "dialética". Mais adiante, irei sugerir uma maneira de fundamentar essas (e outras) perspectivas que não recorre a invocar uma distinção entre processo e procedimento.

\section{O Triunvirato}

A ideia por trás do que chamei de "Visão do Triunvirato" é as que as três perspectivas - o lógico, o dialético e o retórico - têm uma contribuição igualmente importante para o estudo da argumentação. Como observado anteriormente, Wenzel não esclarece o que ele entende por perspectiva, mas podemos fazer inferências a partir do que ele disse, o que nos permitirá 
esmiuçar o conceito. Ele afirma que cada uma dessas perspectivas está fundamentada na tradição humanista ocidental (WENZEL, 1990, p. 12). Ele se refere ao fato de que "diferentes tradições de pesquisa se fundamentam em distintas perspectivas" (WENZEL, 1990, p. 11). Quando ele escreve que "a argumentação depende igualmente dos recursos da lógica, da dialética e da retórica", é tentador concretizar isso com referência à lógica, à dialética e à retórica como disciplinas, posto que cada uma delas desenvolveu ferramentas e recursos para tratar da argumentação. . O problema óbvio desse tipo de associação é que, embora exista uma perspectiva dialética, não existe - que eu saiba - uma disciplina chamada "dialética", que estude a argumentação ainda que tenha existido localmente no passado (cf. LEFF, 2002). Voltaremos a esse ponto em breve. Por ora, continuemos a ver como Wenzel esmiúça cada um desses componentes.

\subsection{Lógica}

Wenzel (1990, p. 9) afirma: “a lógica nos ajuda a entender e avaliar argumentações como produtos que as pessoas criam quando discutem". Uma questão que surge, neste momento, relaciona-se aos critérios utilizados na avaliação. A posição de Wenzel parece um tanto ambígua para mim. Quando ele fala sobre lógica, parece ter em mente, em alguns casos, a lógica formal tradicional e, em outros casos, a lógica informal. Quando ele afirma que "os lógicos podem dizer: 'um bom argumento é aquele em que uma alegação claramente declarada é sustentada por evidências aceitáveis, relevantes e suficientes"', ele remete a critérios altamente associados à lógica informal. Todavia, mais adiante, ele escreve que "a teoria lógica se refere aos padrões e aos critérios usados para distinguir argumentos corretos dos incorretos" (WENZEL, 1990, p. 15). O termo "correção" é frequentemente associado à lógica formal, à visão de que um bom argumento é um argumento correto e de que um argumento correto é aquele que tem premissas verdadeiras e é válido (não está claro que seja esse o significado que está sendo invocado no excerto). As diferenças entre a lógica informal e a lógica formal estão largamente (mas não exclusivamente) associadas aos critérios apropriados para a avaliação de argumentos. Historicamente, a lógica informal se originou da insatisfação com a abordagem adotada pela lógica tradicional (dedutiva 
formal) para a avaliação de argumentos que apresentavam validade dedutiva. Portanto, no que se refere aos critérios que devem ser aplicados na avaliação de argumentos, essas duas lógicas abordagens distintas - e talvez incompatíveis. Isso significa - e este é o ponto relevante para essa discussão que não se pode falar facilmente "da perspectiva lógica". Antes, deve-se reconhecer que há uma série de "perspectivas" dentro da perspectiva lógica: a perspectiva da lógica dedutiva, da lógica indutiva, da lógica informal etc. Existem muitas outras lógicas - lógica modal, lógica epistêmica etc. -, mas, neste artigo, estamos preocupados com as lógicas que têm uma relação direta com a argumentação.

\subsection{Retórica}

Wenzel (1990, p. 9) escreve que, "como primeira afirmação geral, podemos dizer que a retórica nos ajuda a entender e avaliar a argumentação como um processo natural de comunicação persuasiva". Um problema imediato que parece nos confrontar ao esmiuçarmos a ideia de perspectiva retórica é: qual visão de retórica deve ser adotada para delinear essa perspectiva? Existem muitas candidatas. Como indica nossa discussão anterior, há Aristóteles (mas qual Aristóteles?5), Perelman (1969) (qual Perelman?), Wenzel (1990), Tindale (1999) e muitos outros cujas perspectivas podem ser classificadas como retóricas.

A não ser no sentido mais geral, parece-me, então, que não existe algo como "a perspectiva retórica". E suspeito que muitos que usam tal sintagma não o fazem como uma descrição definida, mas como "um exemplo de uma abordagem retórica". No entanto, isso não proporciona muito conforto, pois seria difícil oferecer uma descrição do que conta como retórico com a qual todos aqueles que se consideram praticantes dessa abordagem concordariam. Por exemplo, a teoria normativa de Perelman faz referência essencial ao auditório universal, mas Johnstone Jr. (1959) e Kock (2009) adotam posições bastante diferentes em relação a questões normativas. Estamos, neste ponto, em uma situação similar à que discutimos em relação à abordagem lógica: parece que também existe uma pluralidade de perspectivas incompatíveis no âmbito de uma perspectiva retórica mais ampla.

${ }^{5}$ Ver Poster (2008). 
Outro problema é que, embora a retórica como disciplina permaneça vital, ela parece ter passado por momentos difíceis no que diz respeito à sua constituição em unidades acadêmicas ${ }^{6}$. Os departamentos de Retórica fecharam e o estudo da retórica foi "desviado" para os Departamentos de Inglês ou talvez para os Departamentos de Comunicação (ou de Estudos de Comunicação). Neste ponto, precisamos fazer uma pausa para observar um importante desenvolvimento: o surgimento de uma nova perspectiva Comunicação -, que tem óbvia relevância para o estudo da argumentação. Pode-se sugerir que essa nova perspectiva possa simplesmente ser incluída na retórica, mas isso parece desprezar a integridade e a autonomia dessa importante e nova área de pesquisa.

Essa reflexão trouxe à tona duas ideias importantes. Primeiro, existem perspectivas incompatíveis no âmbito das perspectivas lógica e retórica. Segundo, novas comunidades e tradições de pesquisa ganharam destaque ou surgiram desde os escritos de Wenzel, de modo que suas perspectivas precisam ser consideradas se pretendermos fazer justiça ao Perspectivismo.

\subsection{Dialética(s)}

Já observei que Wenzel (1990, p. 9) considera a dialética um procedimento (ou método ou sistema) para regular as discussões entre as pessoas. Ele escreve: "a dialética nos ajuda a entender a avaliação da argumentação como um método cooperativo para tomar decisões críticas". Ele afirma que a forma mais simples de dialética é a descrita nos diálogos de Platão. Aristóteles escreveu sobre o método da seguinte forma: sendo capazes de analisar qualquer dificuldade em ambos os sentidos possíveis, mais facilmente detectaremos em cada questão onde está a verdade e onde [está] o erro" “ (Tópicos, 101a. 35, colchetes dos tradutores)․ Wenzel escreve:

No âmbito da perspectiva dialética, os principais recursos são projetos ou planos para conduzir discussões críticas. O termo "discussão" é usado para incluir todos os tipos de interação comunicativa, desde conversas simples até debates formais. Qualquer uma dessas interações é "dialética” desde que motivada pelo

\footnotetext{
${ }^{6}$ Existe uma conexão bastante forte entre unidades acadêmicas e disciplinas, por um lado, e também entre disciplinas e perspectivas (e sub-perspectivas), por outro.

7 N.T.: Tradução extraída de ARISTÓTELES. Tópicos. Tradução de José Segurado e Campos. Lisboa: Imprensa Nacional - Casa da Moeda, 2007.
} 
desejo de examinar uma pergunta criticamente por meio de procedimentos sistemáticos (WENZEL, 1990, p. 21).

No entanto, como veremos em breve, há uma variação considerável em como entender o que constitui uma perspectiva dialética.

Para concluir a parte expositiva do meu artigo, assinalo que, embora eu considere que haja utilidade e validade no que chamei de Visão do Triunvirato, as preocupações vêm se acumulando. Debrucemo-nos sobre isso agora.

\section{Algumas preocupações acerca do Triunvirato}

Um triunvirato é governado por três partes. Essa maneira de falar corre o risco de criar uma presunção que falha em reconhecer a legitimidade e a importância de outras perspectivas. Wenzel (1990, p. 25) está ciente deste perigo:

Você não deve esperar que essas perspectivas revelem tudo o que você pode querer entender sobre argumentação; existem muitas outras abordagens, algumas das quais estão representadas em outros capítulos deste livro. No entanto, retórica, dialética e lógica são centrais no estudo da argumentação ${ }^{8}$.

O uso continuado do trio de formas adjetivas - lógico, dialético e retórico - pode nos levar a ignorar o que Wenzel reconhece no excerto: o fato de que outras perspectivas, além dessas três, têm propostas e contribuições importantes para o estudo da argumentação. Como observado anteriormente, existe uma abordagem comunicativa para o estudo da argumentação que está bastante separada da retórica. E as contribuições da linguística? Neste espaço, pode-se mencionar prontamente o trabalho de teóricos como Anscombre e Ducrot (1983) e também Zagar (1996) ${ }^{9}$. Não penso que iniciativas como essas possam ser prontamente alocadas em termos do triunvirato. Ainda mais importante é reconhecer o enorme impacto gerado pelos nossos colegas de Ciência da Computação, quando os estudiosos desviaram seu foco do conhecimento para a argumentação, uma mudança

\footnotetext{
8 Uma nota semelhante é deixada pelos editores da obra coletiva, os quais dizem que "precisamos explicar nossas perspectivas, reconhecendo que outras perspectivas podem ser tão legítimas quanto as que adotamos" (TRAP; SCHUETZ, 1990, p. 2), mas eles não mencionam nenhuma.

${ }^{9}$ Para uma breve abordagem desses autores, conferir van Eemeren et al. (1996, p. 350-353).
} 
significativa que se deu há cerca de 20 anos. Jürgen Dix et al. escreveram recentemente:

Os primeiros artigos sobre argumentação em ciência da computação apareceram cerca de 20 anos atrás. Desde então, temos visto grandes avanços, com o estabelecimento de uma base teórica sólida, uma ampla gama de aplicações e, mais recentemente, algumas implementações realistas. O campo passou da infância para a maturidade, e as perguntas iniciais que os pesquisadores elaboraram - "como fazemos isso?", "para que serve?" e "como implementamos?" - foram em grande parte respondidas (DIX et al. 2008).

A referência contínua ao triunvirato pode contribuir para negligenciar ou marginalizar as contribuições de outras perspectivas. Não estou dizendo que a aceitação da Visão do Triunvirato cause tendências exclusivistas, mas pode muito bem apoiá-las.

Minha segunda preocupação retoma o ponto exposto acima em relação à retórica: com exceção dos sentidos mais gerais e vagos, parece-me que não existe algo como "a perspectiva retórica". Quando se trata "da perspectiva lógica", é possível encontrar algo que se aproxime da unanimidade no que tange àlógica formal. Mas essa é apenas uma das maneiras pelas quais "a perspectiva lógica" pode ser aplicada. Se partíssemos de uma implementação distintas - a saber, a lógica informal -, encontraríamos algumas variações em relação ao significado de lógica informal e a como seria essa abordagem. Mesmo aqui na Universidade de Windsor - a casa da lógica informal -, enquanto Johnson e Blair concordam em certas coisas sobre a lógica informal, eles discordam em outras (sobre a necessidade de uma camada dialética, sobre a lógica informal poder ou dever ser caracterizada em termos da busca por um terceiro tipo ligação entre premissas e conclusão, para citar apenas dois). Por isso, é importante observar que aqueles que trabalham com lógica informal (ou que dizem que o fazem) fazem coisas bastante diferentes sob esse rótulo. Neste ponto, vemos, novamente, alternativas incompatíveis no âmbito de uma dada perspectiva.

Quando se trata da "perspectiva dialética", surgem problemas ainda maiores. Finocchiaro (2003, p. 13) afirma que "a abordagem dialética se tornou a dominante na teoria da argumentação". Uma lista parcial de autores que fizeram uso essencial do termo dialética/dialético para caracterizar uma abordagem argumentativa incluiria os seguintes nomes: Hamblin (1970); 
Wenzel (1980; 1990); Barth \& Krabbe (1982); van Eemeren \& Grootendorst (1984; 1988; 1992); Blair \& Johnson (1987); Finocchiaro (1987; 2003); Blair (1998; 2003); Johnson (2000); Walton \& Godden (2007).

Não tenho certeza de que a abordagem dialética tenha se tornado dominante, mas certamente ganhou destaque. Por quê? Vários fatores podem ajudar a explicar a ênfase recente. Eu apontaria o surgimento da lógica do diálogo nos anos 1960 (com a Escola de Erlanger); o trabalho de Barth \& Krabbe sobre a lógica do diálogo nos anos 1970 e 1980; a a ideia de uma dialética formal, elaborada porHamblin; e a emergência da abordagem pragmadialética nos anos 1980 com van Eemeren \& Grootendorst (1984; 1992). Ao revisar as referências feitas por muitos autores diferentes que fizeram uso do termo "dialético" em conexão com uma abordagem ao estudo da argumentação, algumas conclusões ficaram flagrantes.

Primeiro, diferentes teóricos (dos quais eu sou um) usaram o termo de maneiras distintas. Blair (1998, p. 337) o fez da seguinte maneira:

Até o momento, a palavra "dialética" não figurou neste artigo. Sua omissão foi deliberada. Uma olhada na literatura sobre argumento e argumentação mostrará que os termos diálogo, dialógico, dialético e dialética são usados de forma intercambiável ou com tanta variação que não marcam distinção aceita.

Segundo, vários teóricos assinalaram essa mesma situação. Assim, Rescher (1977, p. XI) diz que "a dialética é, por assim dizer, a alquimia da filosofia. É tudo para todos os homens". Blair \& Johnson (1987, p. 102) afirmam, em uma nota, que "[...] dialético é um termo muito usado, com muitos sentidos. Quem o usa deve a seus leitores uma explicação do significado particular que lhe atribui" ${ }^{10}$. Tindale (1999, p. 43) diz: "existem vários sentidos de 'dialético"'. Mas, como as referências a Hamblin e Rescher indicam, podemos observar como características comuns o intercâmbio de pontos de vista no âmbito de um diálogo, regido por regras, orientado a resolver uma disputa. Eu diria que, embora nem todos os sentidos sejam capturados pela explicação de Tindale ${ }^{11}$, muitos o são.

\footnotetext{
${ }^{10}$ Tenho a impressão de que a maioria dos teóricos seguiu esse conselho.

${ }^{11}$ A caracterização de Leff (2002) não é abarcada, nem o que Finocchiaro (2003) chama de contraste dialético-monolético.
} 
Terceiro, fiquei impressionado não apenas pela variedade de explicações do significado do termo (que pode ou não convergir em algum sentido central), mas também pela variedade de usos a que o termo foi submetido. Funciona de maneira diferente para Rescher (1977) em Dialectics [Dialética] e para Hamblin (1970) em Fallacies [Falácias]. Rescher se apropriou do termo a partir da tradição da disputa medieval, a fim de remediar um defeito na epistemologia, que pode ser atribuído a Descartes. Hamblin, por outro lado, se apropriou de Aristóteles ao usar o termo "dialética" para designar o estudo que deve concluir o trabalho iniciado pela lógica formal. Hamblin (1970, p. 254) afirma que "uma análise da falácia deve se ancorar em uma dialética formal". Assim, para Hamblin, a dialética formal completa a lógica ${ }^{12}$.. É digno de nota o fato de o termo "dialético" já ter aparecido no início de Fallacies, quando Hamblin está discutindo a tarefa de encontrar um conjunto apropriado de critérios para a argumentação e já rejeitara critérios aléticos e epistêmicos. Nesse texto, ele desenvolveu a noção de critérios dialéticos:

Dificilmente podemos afirmar que um argumento não é um argumento porque procede ex concesso, ou que tais argumentos não têm critérios racionais de valor. Na verdade, estamos falando sobre a classe de argumentos que Aristóteles denominou dialético [...] (HAMBLIN, 1970, p. 241).

Observamos, no excerto, que pode muito bem haver uma tensão entre dois significados de "dialético" um tanto diferentes no âmbito dessa mesma perspectiva.

Esses dois autores entendem "dialética" de maneira distinta do que o fazem Barth \& Krabbe (1982), os quais trabalham na tradição da lógica do diálogo, que remonta à Escola de Erlangen. A lógica do diálogo aborda a argumentação como um processo, um diálogo, um intercâmbio entre um proponente e um oponente, no qual a tarefa da lógica é estabelecer as normas para a condução do diálogo: a atribuição de direitos e deveres na definição do diálogo ${ }^{13}$. Essas concepções, por sua vez, influenciaram van Eemeren \& Grootendorst (1984, p. 199), que afirmam ter aproveitado as ideias de Barth \& Krabbe (1982), incorporando o termo no nome de seu projeto - a abordagem pragmadialética -, que talvez tenha sido o desenvolvimento mais

\footnotetext{
${ }^{12} \mathrm{Na}$ abordagem de Hamblin, a retórica não desempenha papel algum, mas vale conferir, da página 69 em diante, sua discussão sobre as relações entre retórica, dialética e lógica.

${ }^{13}$ Para um tratamento mais completo da lógica do diálogo, consulte Barth (2002).
} 
proeminente na história moderna desse termo complexo. Mas, neste ponto, devemos observar uma diferença importante em seus respectivos entendimentos de "dialética". As normas da pragmadialética não são normas lógicas e não são apresentadas como tais. A pragmadialética está fora do escopo da lógica do diálogo, como foi concebida por Barth \& Krabbe (1982).

O leitor pode ter observado outro fator complicado que paira sobre esta discussão, a saber, a proeminência (e, por vezes, de fato, a co-ocorrência) do termo “dialógico". Finocchiaro (1987, p. 82) diz:

Com relação às abordagens que podem ser rotuladas como retóricas e dialéticas, eu começaria delimitando o significado desses termos da seguinte maneira. Eu conceberia o retórico no sentido de Perelman, como significado vinculado à persuasão. E consideraria dialético como dialógico, isto é, referente ao diálogo.

Este texto é uma fonte possível da fusão de dois termos que, ao que me parece, não devem ser mesclados. Felizmente, tenho um colega que assinalou muito bem essa mesma posição. Blair escreve (1998, p. 338):

Isso nunca acontecerá, mas seria bom se o termo "dialético" fosse reservado para as propriedades de todas as argumentações que envolvem dúvidas ou desacordos com pelo menos dois lados, e o termo "dialógico" fosse reservado para aquelas que envolvem exclusivamente o intercâmbio de turnos verbais. Em seguida, poderíamos usar essa terminologia para expressar que (1) toda argumentação é dialética, mas, de modo algum, toda argumentação é dialógica; e (2) as propriedades dialéticas dos diálogos e as normas derivadas do modelo de diálogo não se aplicam para intercâmbios argumentativos não-dialógicos, mesmo que estes também sejam dialéticos.

Revendo a variedade de significados, usos e funções que foram rotulados como "dialéticos", concluo que, dos três termos amplamente utilizados para designar perspectivas sobre o estudo da argumentação, "dialético" parece ser o mais problemático. Parece ter a maior variedade e a história mais complicada. Do meu ponto de vista, esse adjetivo - dialético tem quatro usos distintos. No primeiro, "dialético" é tomado em relação à área de pesquisa conhecida como dialética. A perspectiva dialética seria aquela adotada por quem estuda dialética. Vimos que, embora existisse uma disciplina desse tipo, atualmente não existe mais. No segundo, "dialético" refere-se a uma perspectiva sobre o estudo da argumentação que, com as perspectivas lógica e retórica, forma o Triunvirato. No terceiro, "dialético" contrasta com abordagens dialógicas, cuja aparente confluência acabamos de 
discutir. No quarto, "dialético" marca uma alternativa às abordagens monoléticas (FINOCCHIARO, 2003, p. 19).

Um problema final é que existem várias maneiras de entender as relações entre os três componentes do Triunvirato. Em uma organização ideal, os membros de um Triunvirato compartilham a tarefa de governar. Wenzel vê a situação como um caso de paridade: cada uma das três perspectivas tem igual papel a desempenhar no estudo da argumentação. Nenhuma se destaca como mais importante do que as outras. No entanto, não encontrei argumento algum no artigo de Wenzel de que essas três perspectivas são de igual importância nem está totalmente claro como se dá essa paridade quando é esmiuçada em detalhes. Isso significa que qualquer teoria viável da argumentação deva ter um componente retórico, um componente lógico e um componente dialético? Ou a alegação deve ser entendida globalmente: que, de maneira geral, o estudo da argumentação requer contribuições das três perspectivas? Quando se trata de teorias individuais, os teóricos veem as coisas de maneira bem diferente. Na Pragmadialética, a perspectiva dialética é fundamental; a retórica é introduzida por meio do que é denominado manobra estratégica; a lógica quase não é mencionada (embora suas produções sejam proeminentes em regras). Para Tindale (1999), a perspectiva retórica é tomada como básica. Em Johnson (2000), atribui-se à perspectiva lógica o papel fundamental.

Contudo, os modos pelos quais as várias perspectivas se relacionam constitui uma situação ainda mais complexa do que a indicada aqui. Para uma análise cuidadosa dos vários tipos possíveis de relação entre essas perspectivas, não posso fazer melhor do que recomendar o artigo de Blair (2003). Mesmo se nos restringirmos ao Triunvirato, vimos que existem divergências fundamentais sobre os papéis atribuídos a cada uma.

\section{Resumo e conclusão}

Escolhi o termo "triunvirato" como um quadro para chamar a atenção ao que considero ser o modo como muitos (inconscientemente) pensam sobre tais questões. Eles adotam esses termos para designar as abordagens dominantes do estudo da argumentação e acreditam que cada uma tem uma contribuição importante a dar. De modo geral, concordo com essa visão, mas 
acredito que há problemas com ela, o que eu espero ter trazido à tona ao propor o termo "triunvirato".

O primeiro problema que mencionei foi o perigo de ser insular, de excluir ou minimizar as importantes contribuições feitas por outras perspectivas. Mencionei estudos de linguística, comunicação e computação, mas também poderia ter mencionado psicologia e epistemologia, ambas com contribuições para o estudo da argumentação.

O segundo problema surgiu da reflexão sobre sintagmas como "a perspectiva retórica" ou "uma perspectiva dialética". Sou levado a fazer a seguinte observação: seria melhor falarmos sobre perspectivas retóricas, perspectivas dialéticas e perspectivas lógicas para reconhecer que existem várias maneiras pelas quais os teóricos poderiam trabalhar no âmbito dessas perspectivas mais amplas.

O terceiro problema estava relacionado às variadas visões sobre a chamada perspectiva dialética. É uma coisa para o pragmadialético, outra para o lógico do diálogo e outra ainda mais distinta para alguns lógicos informais. Sugeri, neste ponto, que podemos minimizar qualquer tipo de mal-entendido adotando a distinção de Blair entre dialético e dialógico.

A quarta preocupação diz respeito à distribuição de poder no seio do Triunvirato. No locus classicus, Wenzel adotou a visão paritária de que as três perspectivas são igualmente válidas, igualmente frutíferas. Mas parece-me que queremos fazer a pergunta: as três são igualmente proveitosas? Mesmo que existam múltiplas perspectivas, isso não quer dizer que tudo será igualmente proveitoso para nos ajudar a entender melhor a argumentação.

Para concluir, as três perspectivas sobre o estudo da argumentação que denominei Triumvirato surgiram ao longo do tempo em várias disciplinas ou comunidades de investigação ${ }^{14}$, todas com tradições e bibliografia (livros, periódicos, enciclopédias) na qual estão alojados seus produtos intelectuais (conceitos básicos, questões, problemas, técnicas, teorias etc.). Eles são identificáveis por sua conexão à área de pesquisa conhecida como retórica, à área de pesquisa conhecida como lógica e a uma abordagem denominada dialética, cujo status é um pouco mais problemático. Em vez de tentar localizar

14 Para uma discussão perspicaz sobre as várias maneiras de interpretar essa ideia, ver McKerrow (1990). 
suas respectivas esferas de influência por meio da distinção processo-produtoprocedimento, tenho sugerido uma alternativa. Os membros dessas comunidades - a comunidade retórica, por exemplo - encontram-se unidos não pelo foco no processo em detrimento do procedimento, nem pela aceitação de qualquer uma das visões sobre o que é retórica, nem por qualquer definição de retórica comumente aceita (tal como acontece com a filosofia), nem mesmo por um entendimento comum do que a perspectiva retórica pareça ser, nem por um acordo sobre quais são as questões cruciais. Eles estão ligados por uma história, uma tradição e uma educação comuns, além de um interesse contínuo em uma ampla gama de questões e problemas.

Parece claro que essas três comunidades têm a experiência mais longa com argumentação, mas isso não deve nos cegar para as variações consideráveis no âmbito de cada uma delas. E o mais importante: isso não deve nos levar a marginalizar ou subestimar as ideias decorrentes de outras tradições e áreas de investigação, isto é, de outras perspectivas.

\section{Agradecimentos}

Gostaria de agradecer aos meus colegas do CRRAR por comentários extremamente úteis e construtivamente críticos em um esboço anterior: J. Anthony Blair, Hans V. Hansen, Catherine Hundleby, Robert C. Pinto, Christopher Tindale e Douglas Walton. Sou grato ao meu ex-aluno Michael Baumtrog por suas perguntas e comentários úteis em uma versão prévia, que levaram a várias revisões no artigo final, e também por sua ajuda na formatação do artigo.

\section{Referências}

ANSCOMBRE, Jean-Claude; Ducrot, Oswald. L'Argumentation dans la langue. Liège: Pierre Mardaga, 1983.

BARTH, Else M. A framework for intersubjective accountability: dialogical logic. In: GABBAY, Dov M.; JOHNSON, Ralph H.; OHLBACH, Hans Jürgen; WOODS, John (Eds.). 
Handbook of the Logic of Argument and Inference. London: Elsevier Science, 2002. p. 225-293.

BARTH, Else M.; KRABBE, Erik C. W. (Eds.). From Axiom to Dialogue: A Philosophical Study of Logics and Argumentation. Berlin: Walter De Gruyter, 1982.

BLAIR, J. Anthony. The limits of the dialogue model of argument. Argumentation, $n$. 12, v. 2, p. 325-339, 1998.

BLAIR, J. Anthony. The relationships among logic, dialectic and rhetoric. In: EEMEREN, Frans H. van; BLAIR, J. Anthony; WILLARD, Charles A.; SNOECK HENKEMANS, Francisca (Eds.). Proceedings of the Fifth Conference of the International Society for the Study of Argumentation. Amsterdam: Sic Sat, 2003. p. 125-131.

BLAIR, J. Anthony; JOHNSON, Ralph H . Argumentation as dialectical. Argumentation, n. 1, p. 41-56, 1987.

DIX, Jürgen; PARSONS, Simon; PRAKKEN, Henry; SIMARI, Guillermo. Theory and Practice of Argumentation Systems. In: Dagstuhl Seminar Proceedings. Leipzig: Schloss Dagstuhl, 2008. p. 1-13.

EEMEREN, Frans H. van; GROOTENDORST, Rob. Speech Acts in Argumentative Discussions. Dordrecht: Foris, 1984.

EEMEREN, Frans H. van; GROOTENDORST, Rob. Rationale for a pragma-dialectical perspective. Argumentation, n. 2, p. 271-291, 1988.

EEMEREN, Frans H. van; GROOTENDORST, Rob. Argumentation, Communication and Fallacies. Hillsdale: Lawrence Erlbaum Associates, 1992.

EEMEREN, Frans H. van; GROOTENDORST, Rob; SNOECK-HENKEMANS, Franscisca et al . Fundamentals of Argumentation Theory. Mahwah: Lawrence Erlbaum Associates, 1996.

EEMEREN, Frans H. van; HOUTLOSSER, Paul (Eds). Dialectic and Rhetoric: The Warp and Woof of Argumentation Analysis. Dordrecht: Kluwer Academic Publishers, 2002.

FINOCCHIARO, Maurice. An historical approach to the study of argumentation. In: EEMEREN, Frans H. van; GROOTENDORST, Rob; BLAIR, J. Anthony; WILLARD, Charles A. (Eds.). Argumentation: Across the Lines of Discipline. Dordrecht: Foris, 1987. p. 8192.

FINOCCHIARO, Maurice. Dialectics, evaluation and argument. Informal Logic, n. 23, p. 19-50, 2003.

HAMBLIN, Charles L. Fallacies. London: Methuen, 1970. 
JOHNSON, Ralph H. Manifest Rationality: A Pragmatic Theory of Argument. Mahwah: Lawrence Erlbaum, 2000.

JOHNSON, Ralph H. Review of "Dialectic and Rhetoric: The warp and woof of argumentation". Argumentation, n. 18, p. 438-488, 2004.

JOHNSTONE, Henry W. Jr. Philosophy and Argument. State College: The Pennsylvania State University Press, 1959.

KOCK, Christian. Choice is not true or false: The domain of rhetorical argumentation. Argumentation, n. 23, v. 1, p. 61-80, 2009.

KRABBE, Erik C. W. Meeting in the house of Callias: An historical perspective on rhetoric and dialectic. In: EEMEREN, Frans H. van; HOUTLOSSER, Paul (Eds.). Dialectic and Rhetoric: The Warp and Woof of Argumentation Analysis. Dordrecht: Kluwer Academic Publishers, 2002. p. 29-40.

LEFF, Michael. The relation between dialectic and rhetoric in a classical and a modern perspective. In: EEMEREN, Frans H. van; HOUTLOSSER, Paul (Eds.). Dialectic and Rhetoric: The Warp and Woof of Argumentation Analysis. Dordrecht: Kluwer Academic Publishers, 2002. p. 53-64.

MCKERROW, Raymie. Argument communities. In: TRAPP, Robert; SCHUETZ, Janice (Eds.). Perspectives on Argumentation: Essays in Honour of Wayne Brockriede. Prospect Heights: Waveland Press, 1990. p. 27-40.

PERELMAN, Chaïm; OLBRECHTS-TYTECA, Lucie. The new rhetoric: A treatise on argumentation. Notre Dame: University of Notre Dame Press, 1969.

PERELMAN, Chaïm. The Realm of Rhetoric. Notre Dame: University of Notre Dame Press, 1982.

POSTER, Carol. Whose Aristotle? Which aristotelianism? Philosophy and Rhetoric, n. 41, v. 4, p. 375-401, 2008.

RESCHER, Nicholas. Dialectics: A controversy-oriented approach to the theory of knowledge. Albany: State University of New York Press, 1977.

SMITH, Robin. Aristotle. In: Stanford Encyclopedia of Philosophy. Disponível em: http://plato.stanford.edu/entries/aristotle-logic. Acesso em: 17 mar. 2017.

TINDALE, Christopher. Acts of Arguing: A Rhetorical Model of Argument. Albany: State University of New York Press, 1999.

TRAPP, Robert; SCHUETZ, Janice (Eds.). Perspectives on Argumentation: Essays in Honour of Wayne Brockriede. Prospect Heights: Waveland Press, 1990. 
WALTON, Douglas W.; GODDEN, David. Informal logic and the dialectical approach to argument. In: HANSEN, Hans V.; PINTO, Robert C. (Eds.). Reason Reclaimed. Newport News: Vale Press, 2007. p. 3-17.

WENZEL, Joseph. Perspectives on argument. In: RHODES, Jack; NEWELL, Sarah (Eds.). Proceedings of the summer conference on argumentation. Speech Communication Association, 1980.

WENZEL, Joseph. Three Perspectives on Argument. In: TRAPP, Robert; SCHUETZ, Janice (Eds.). Perspectives on Argumentation: Essays in Honour of Wayne Brockriede. Prospect Heights: Waveland Press, 1990. p. 9-16.

ŽAGAR, Igor $\check{Z}$. Argumentation in language as opposed to argumentation with language. In: EEMEREN, Frans H. van; GROOTENDORST, Rob; BLAIR, J. Anthony; WILLARD, Charles A. (Eds.). Proceedings of the Third ISSA Conference on Argumentation. Amsterdam: Sic Sat, 1996. p. 200-218.

Tradução

Eduardo Lopes Piris

Docente da Universidade Estadual de Santa Cruz (UESC)

Paulo Roberto Gonçalves-Segundo

Docente da Universidade de São Paulo (USP)

\section{Forma de citação sugerida}

JOHNSON, Ralph H. Revisitando o triunvirato lógica/dialética/retórica. Tradução: Eduardo Lopes Piris e Paulo Roberto Gonçalves-Segundo. EID\&A - Revista Eletrônica de Estudos Integrados em Discurso e Argumentação, Ilhéus, n. 20, v. 1, p. 254-273, 2020. DOI 10.17648/eidea-20-v1-2708. 